\title{
TI.114.1
}

\section{Internet2 Trust and Identity Accomplishments}

- PDF: 2016TIReport.pdf

- Text: 2016TIReport.txt

\section{More Information}

\begin{tabular}{|l|l|}
\hline Repository ID & TI.114.1 \\
\hline Persistent URL & http://doi.org/10.26869/TI.114.1 \\
\hline Title & 2016 Internet2 Trust and Identity Accomplishments \\
\hline Authors & Internet2 Trust and Identity Executive Management \\
\hline Sponsor & Internet2 Trust and Identity Executive Management \\
\hline Review & \\
\hline Status & Legacy \\
\hline Publish Date & February 28, 2017 \\
\hline DOI & $10.26869 /$ TI.114.1 \\
\hline Signature & \\
\hline Deprecated & No \\
\hline Future Review & \\
\hline Supersedes & \\
\hline Format & PDF, Text \\
\hline Related Docs & \\
\hline Development Location & \\
\hline IP Framework & \\
\hline Subject Tags & middlewarerescue, incommon \\
\hline Notes & \\
\hline & \\
\hline
\end{tabular}

